\title{
Some arguments that the mental logic theory needs to clarify to continue being an alternative to the mental models theory ${ }^{1}$
}

\section{Algunos argumentos que la teoría de la lógica mental necesita aclarar para continuar siendo una alternativa a la teoría de los modelos mentales}

Recibido: 04 de agosto de 2015 - Revisado: 31 de marzo de 2016 - Aprobado: 11 de mayo de 2016.

Miguel López-Astorga ${ }^{2}$

\begin{abstract}
Undoubtedly, the mental models theory has become an important theory in cognitive science. This theory can predict and explain most of the experimental results that the literature of that field shows. This fact can lead one to think that human mental processes are essentially semantic and that the syntactic approaches can no longer be held. In this way, in this paper, I try to analyze a framework based on formal rules, the mental logic theory, which also seems consistent with the experimental results, and review some of the reasons that its proponents often give in order to prove that it is worth continuing to consider it as an explicative alternative to the mental models theory. However, I show that such reasons can be questioned from the mental models theory and that, therefore, they need to be explained in a clearer way.
\end{abstract}

\section{Keywords}

Semantics, syntax, formal rules, mental logic, mental models.

\section{Resumen}

Indudablemente, la teoría de los modelos mentales se ha convertido en una teoría importante en el ámbito de la ciencia cognitiva. Esta teoría puede predecir y explicar la mayoría de los resultados experimentales que se hallan en la literatura. Tal hecho puede llevar a pensar que los procesos mentales humanos son esencialmente semánticos y que en el presente ya no es posible defender enfoques sintácticos. En este sentido, en este trabajo, trato de analizar un marco basado en reglas formales, la teoría de la lógica mental, que también parece consistente con los resultados experimentales, y de revisar algunas de las razones que sus defensores ofrecen a menudo para probar que puede ser productivo continuar considerándolo como una alternativa explicativa a la teoría de los modelos mentales. No obstante, muestro que esas razones pueden ser cuestionadas desde la teoría de los modelos mentales y que, por tanto, necesitan ser explicadas de un modo más claro.

\section{Palabras clave}

Semántica, sintaxis, reglas formales, lógica mental, modelos mentales.

\footnotetext{
Este artículo es resultado del Proyecto N. I003011, "Algoritmos adaptativos e inferencias lógicas con enunciados condicionales", apoyado por la Dirección de Investigación de la Universidad de Talca, Chile) El autor, que es el investigador principal del proyecto, agradece a las instituciones mencionadas por su ayuda en la financiación de este documento y a los expertos anónimos que lo revisaron por sus comentarios, lo que sin duda mejoró la versión final.

${ }^{2}$ Doctor en Lógica y Filosofía de la Ciencia por la Universidad de Cádiz, España. Licenciado en Filosofía y Ciencias de la Educación por la Universidad de Sevilla, España. Docente del Instituto de Estudios Humanísticos "Juan Ignacio Molina", Universidad de Talca, Chile.

Correo electrónico: milopez@utalca.cl

Para citar este artículo use: LópezAstorga, M. (2016). Some arguments that the mental logic theory needs to clarify to continue being an alternative to the mental models theory. Civilizar Ciencias Sociales y Humanas, 16(31), 235-248.
} 


\section{Introduction}

It is obvious that the mental models theory (from now on, MM), which is explained, described, and commented on in papers such as, for example, Byrne and Johnson-Laird (2009), Johnson-Laird (1983，2001，2006, 2010, 2012, 2015), Johnson-Laird, Byrne, and Girotto (2009), Khemlani and Johnson-Laird (2009), Oakhill and Garnham (1996), or Orenes and Johnson-Laird (2012), is a very relevant theory at present. In addition to the fact that it has wide acceptance in the field of psychology of reasoning and cognitive science, MM has proved to be consistent with almost all the experimental results that can be found in the literature on cognition. For these reasons, it can be thought that this theory is the theory that best accounts for human inferential activity, that it is right to claim that mental processes are basically semantic, and that neither syntax nor logical forms play any role in such processes.

Thus, it seems that MM is revealing that formal approaches such as that of Rips (1994) or that of the mental logic theory (e.g., Braine \& O'Brien, 1998a; O'Brien, 2009, 2014; O'Brien $\& \mathrm{Li}, 2013$ ) must be overcome. However, this last theory, the mental logic theory (from now on, ML), is also coherent with many of the experimental findings reported by the literature on cognitive science, and, for this reason, its proponents state that there is no conclusive evidence that leads to its absolute rejection, and that the literature fails to demonstrate that it is a mistaken or incorrect theory.

My aim in this paper is to show that, while it is true that ML can offer arguments in its favor, it is also true that MM can easily respond to those arguments and that, if the proponents of ML want their theory to continue to be an alternative to be considered, they must necessarily clarify certain aspects of it. I will expose and explain in details all of this in the next pages. To do that, I will base on not only works such as those cited above, but also other papers in which the discussion between the two approaches is more explicit (e.g., López-Astorga, 2014a, 2014b, 2015a, 2015b, 2015c, 2016a; O’Brien, Braine, \& Yang, 1994; Schroyens, Schaeken, \& D'Ydewalle, 2001). In this way, I think that what is appropriate is to start by describing the general theses both of MM and ML.

\section{The semantic approach of MM}

As said, MM is fundamentally a semantic theory. It states that syntax is not important in human reasoning and that individuals, when they reason, pay attention to the semantic possibilities or models of propositions. In this way, what people do is to look for the models in which, if the premises are true, the conclusion is true too.

One interesting point of $\mathrm{MM}$ is that individuals do not always identify all the models to which the propositions refer. Thus, it distinguishes between 'mental models' and 'fully explicit models'. People immediately and easily detect the mental models. However, the fully explicit models can only be noted if a greater effort is made. Each logical connective, conjunction, disjunction, conditional, and biconditional, has its models, but I will only consider here, as an example, the conditional. According to $\mathrm{MM}$, a proposition such as 'if $\mathrm{A}$ then B' has a mental model:

\section{$\mathrm{A}$ and $\mathrm{B}$}

Nonetheless, its fully explicit models are the following:

$$
\begin{aligned}
& \mathrm{A} \text { and } \mathrm{B} \\
& \neg \mathrm{A} \text { and } \mathrm{B} \\
& \neg \mathrm{A} \text { and } \neg \mathrm{B} \\
& \text { Where ' } \neg \text { ' denotes negation. }
\end{aligned}
$$

In this way, it is not hard for MM to explain phenomena such as the fact that the modus ponens rule is often less difficult than the modus tollens rule for individuals (see, for example, Byrne \& 
Johnson-Laird, 2009). As it is well known, the modus ponens schema is this one:

If $\mathrm{A}$ then $\mathrm{B}$

A

Ergo B

Given that, as mentioned, the mental model of the conditional is 'A and B', it is evident, following $\mathrm{MM}$, that, in a scenario in which it is known that 'if $\mathrm{A}$ then B' and ' $\mathrm{A}$ ' are true, most people will tend to draw that ' $\mathrm{B}$ ' is true too. Nevertheless, the case of the modus tollens rule is different. As is also well known, its schema is as follows:

If $\mathrm{A}$ then $\mathrm{B}$

$\neg \mathrm{B}$

Ergo $\neg \mathrm{A}$

As can be noted, ' $\neg$ A' can only be derived from 'if A then B' and ' $\neg \mathrm{B}$ ' if the fully explicit models are taken into account, in particular, the model ' $\neg \mathrm{A}$ and $\neg \mathrm{B}$ '. So, because it is more difficult for individuals to consider the fully explicit models than to detect the mental models, it is clear, according to MM, why modus ponens is often easier than modus tollens.

This example may serve as an illustration of how MM explains and predicts individuals' behavior in reasoning tasks. The literature on MM is extensive, but, in my view, the above description of the problems of modus ponens and modus tollens provides a clear idea about its general framework. In any case, more aspects of this theory will be commented below.

\section{The syntactic approach of ML}

Nonetheless, ML offers a syntactic framework. The main thesis of ML seems to be that human reasoning works following formal rules and its adherents have proposed a number of such rules, which have not been selected randomly, but in accordance with empirical results. In other words, ML only accepts the formal rules that, according to experiments reported in the literature on reasoning, people really use.

In this way, ML distinguishes different types of rules (see, e.g., Braine \& O'Brien, 1998b): 'Core Schemas', which are used as often as possible, 'Feeder Schemas', which are used as often as necessary, 'Incompatibility Schemas', which refer to contradictions, and 'Other Schemas', which play a limited role in the 'Direct Reasoning Routine' and are more linked to learned abilities.

Core Schemas are a set of basic and simple rules. Some of them are, for example, a version of the modus tollendo ponens rule:

A1 or... or An, $\neg \mathrm{Ai}$; ergo $\mathrm{A} 1$ or... or $\mathrm{Ai}-$ 1or $\mathrm{Ai}+1$ or... or An (schema 3 in Braine \& O'Brien, 1998b, p. 80. 'A1 or... or An' and ' $\neg \mathrm{Ai}$ ' are premises; on the other hand, what is after the word 'ergo', i.e., 'A1 or... or Ai-1or $\mathrm{Ai}+1$ or... or An' is the conclusion).

And the modus ponens rule (schema 7 in Braine \& O'Brien, 1998b). A representative Feeder Schema is, on the other hand, the conjunction elimination rule:

A1 and... and Ai and... An; ergo Ai (schema 9 in Braine \& O’Brien, 1998b, p. 80).

Obviously, an Incompatibility Schema is this one:

A, $\neg$ A; ergo INCOMPATIBLE (schema 10 in Braine \& O'Brien, 1998b, p. 81).

Finally, the set of Other Schemas includes rules such as that of conditional introduction:

[A(supposition); ergo B]; ergo if A then B (schema 12 in Braine \& O’Brien, 1998b, p. 81). 
But a very interesting aspect of ML is that it contains a program that describes reasoning processes and the order in which the rules or schemas are applied (see Braine \& O'Brien, 1998 b, pp. 82-83). Thus, ML is a system that also has great explanatory and predictive potentialities, and this fact can be seen if the case of modus ponens and modus tollens of the previous section is considered again. It is evident that, according to ML, individuals can easily make inferences with a structure similar to modus ponens, since, as mentioned, modus ponens is a Core Schema and it is an inference with only three steps:

(1) p -> q (premise)

(2) $\mathrm{p}$ (premise)

(3) q (S7 1, 2)

Where ' $>$ ' stands for conditional relationship and 'S7' represents 'schema 7', (i.e., as said, the modus ponens rule).

However, modus Tollens is more complex. It is not a Core Schema (it is not even a schema in ML) and, therefore, it requires more inferential steps. According to ML, the modus tollens rule involves an 'Indirect Reasoning Strategy' (so it is not part of the Direct Reasoning Routine), in particular, the 'Reductio ad Absurdum Strategy', which refers, in a similar way as it does in standard propositional calculus, to the need of denying an assumption when a contradiction is found. In this way, the inference corresponding to the modus tollens is this one:

(1) p -> q (premise)

(2) $\neg$ q (premise)

(3) p(assumption)

(4) q (S7 1, 3)

(5) Incompatibility (S10 2, 4)

Where 'S10' is 'schema 10'.
As can be noted, two more steps are needed, regardless of the fact that an assumption is required and that Reductio ad Absurdum is one of the "secondary late-acquired skills, which are subject to individual variation, although common in adult subjects" (Braine \& O’Brien, 1998b, p. 79).

In this way, it can be said that ML can also explain and predict many cognitive phenomena. For this reason, ML can claim that the indisputable experimental support that MM has does not necessarily mean that ML cannot be accepted. In this way, given that ML is also consistent with several empirical results reported by the experiments carried out by the proponents of MM, some arguments in favor of ML can be given too. The following are some of them.

\section{Reasons in favor of ML}

\section{ML only explains certain inferen- tial processes, not all of them.}

In the literature on cognitive science, many logical reasoning tasks that people do not often solve correctly are to be found. Orenes and Johnson-Laird (2012) indicate some clear examples. One of them is the following:

"David visited England. Does it follow that David visited Paris or he visited England?" (Orenes \& Johnson-Laird, 2012, p. 375).

If we assume that ' $\mathrm{V}$ ' is the logical disjunction, that ' $p$ ' stands for 'David visited Paris', and that ' $q$ ' means 'David visited England', the structure of this task is very simple and easy:

q

Ergo p V q?

According to standard propositional calculus and frameworks such as that of Gentzen 
(1935), the response would be positive because this task only needs the use of a simple and basic rule, the disjunction introduction rule (q; ergo $p \mathrm{~V} \mathrm{q}$ ). Nevertheless, in one of their experimental conditions, Orenes and Johnson-Laird (2012) checked that their participants tended to answer 'no' in tasks akin to this one.

Obviously, Orenes and Johnson-Laird's (2012) results enable to think that the human mind does not work in accordance with formal rules because, if this were the case, individuals would respond affirmatively in tasks such as that described. Nonetheless, it can also be thought that their results only mean that the human mind is not led by standard propositional logic or systems such as that of Gentzen. As indicated, ML is not classical logic and it only admits some rules of that logic, in particular, the rules that empirical evidence suggests. In fact, the disjunction introduction rule is not a valid schema in ML and so Orenes and Johnson-Laird's (2012) results are not only compatible with the theses of ML, but also predicted by ML.

Besides, according to ML, even in the case that we noted that the participants in experiments do not use some of the schemas proposed by it, that fact would not demonstrate that ML is an incorrect theory. Another relevant aspect of ML is that, as argued by O'Brien (1998), ML does not claim exclusivity. The fact that there is a mental logic in the human mind does not mean that the human mind only works following that mental logic, or that it always works following that logic. In his view, it seems inappropriate to link the different cognitive approaches on reasoning (including, of course, MM and ML) by means of an exclusive disjunction. Different theories may co-exist and, if it is proved that one of those theories is the only theory that can account for a particular cognitive phenomenon or a particular experimental result, it does not mean that the other theories do not hold. It is possible that several theories are valid at the same time, and that some of them can explain certain phenomena that the other theories cannot.
In this way, it can be said, for example, that ML is absolutely compatible with frameworks such as that of the dual-process theory (e.g., Evans, 2008; Reyna, 2004; Stanovich, 1999, 2004, 2012). The dual-process theory states that there are two different systems or types of reasoning in the human mind. The first one (which is often denominated ' $\mathrm{S} 1$ ' or ' $\mathrm{T} 1$ ') refers to heuristics and biases, and the second one (which is often named 'S2' or 'T2') is linked to people's analytical abilities, i.e., to logical reasoning. Thus, it can be thought that, in certain occasions, the human mind is led by heuristics or biased (i.e., by $\mathrm{S} 1$ or, if preferred, T1) and that, in other cases, its conclusions are logical (when it is led by $\mathrm{S} 2$ or, if preferred, T2). It can hence be assumed that, only in these last cases, individuals reason using a mental logic such as that described by ML, since, in short, ML does not state that human beings are always logically thinking.

Thus, an interesting idea could be to assume that ML and MM can be accepted at the same time. Regardless of the fact that some studies suggest that there are links between the semantic and the syntactic approaches to reasoning (e.g., López-Astorga, 2013, 2014c), ML, although with certain concerns, explicitly admits the possibility of inferences based on mental models. In this connection, O'Brien says, "I make no claim that people never use mental models - only that inferences from mental models would cohabit with inferences from other sources, including those of a mental logic" (O'Brien, 1998, p. 42). Therefore, from this point of view, it can be thought that to carry out experiments in order to prove that ML does not hold is not a too productive task.

On the other hand, it is true that there are empirical findings that, at least until now, only appear to be explained by MM. However, due to the above, ML does not consider such findings to be a difficulty. Some of such empirical results can be found, for example, in Orenes and Johnson-Laird's (2012) paper. As indicated, 
both MM and ML can account for the fact that people do not apply the disjunction introduction rule. Nevertheless, Orenes and Johnson-Laird (2012) state that only MM can account for the action of modulation in problems related to that rule.

According to $\mathrm{MM}$, there are modulation mechanisms linked to pragmatic factors and to the contexts and the meanings of propositions. Thus, in its view, those modulation mechanisms can cause certain models to be blocked. If we take the previous example (that related to David, Paris, and England) into account again, it can be said that MM explains why people do not accept the inference by means of the following argument: inclusive disjunctions have these three fully explicit models:

\section{$\mathrm{A}$ and $\mathrm{B}$}

$\mathrm{A}$ and $\neg \mathrm{B}$

$\neg \mathrm{A}$ and $\mathrm{B}$

In this way, this means that, in the mentioned example, the possibilities corresponding to the conclusion are as follows:

David visited Paris and David visited England

David visited Paris and David did not visit England

David did not visit Paris and David visited England

Orenes and Johnson-Laird (2012) think that the problem is the second possibility (David visited Paris and he did not visit England), since it is inconsistent with the premise (David visited England). So, in their view, if MM is right, a modulation of the conclusion that removes that problematic possibility should cause individuals to accept the inference. Thus, they propose this modulated version:

"Paco visited France. Does it follow that Paco visited Paris or he visited France?" (Orenes \& Johnson-Laird, 2012, p. 375).
As it can be noted, now the possibilities of the conclusion are only:

Paco visited Paris and Paco visited France

Paco did not visit Paris and Paco visited France

The second possibility has disappeared because it is not possible that Paco visits Paris and he does not visit France. For this reason, Orenes and Johnson-Laird's (2012) prediction is that, in cases such as this one, their participants will admit the conclusion, and, indeed, their prediction was confirmed, since most of their participants answered positively to the question in experimental conditions such as the previous one.

Although they do not refer to the explanation indicated by me above (that related to the fact that ML does not accept the disjunction introduction rule), but to others, Orenes and Johnson-Laird (2012) acknowledge that the formal theories can explain why people do not admit versions such as the first one (that related to David, Paris, and England), but the key is, in their opinion, that those theories cannot explain why individuals tend to admit the modulated versions. But the proponents of ML can think that this fact is not a problem for their theory and they can give at least two reasons in this regard.

On the one hand, ML also considers pragmatics to play a role in human thought and hence it is possible that the adherents of ML can offer an account of this phenomenon based only on their assumptions in the future (in fact, López-Astorga, 2015a, already offers some lines or ideas to look for that account from ML). Nevertheless, on the other hand, if that were not the case, it would not imply that ML must be rejected. As said, ML can co-exist with other theories and it is not a problem for it that a particular empirical result can only be explained by MM. The fact that human beings have a mental logic does not mean that they never reason using, for example, mental models. 


\section{Pragmatics has an influence on reasoning.}

As mentioned, ML considers the role of pragmatics in human reasoning. This role is clearly explained, for example, in Braine and O'Brien (1998c). In that work, a previous experiment is commented. That experiment consists of the following text:

John went in for lunch. The menu showed a soup's salad special, with free cola or coffee. Also, with the minute steak you got a free glass of red wine. John chose the soup'n salad special with coffee, along with something else to drink...

a) John got a free cola? (Yes, No, Can't tell)

b) John got a free glass of red wine (Yes, No, Can't tell)" (Braine \& O’Brien, 1998c, p. 46).

Braine and O'Brien (1998c) state that the answer both to (a) and to (b) is 'No'. However, it can be thought that, in principle, it appears that mental logic cannot account for those answers, since the premises are:

(1) $p->(q V r)$ (premise)

(2) $\mathrm{s}->\mathrm{t}$ (premise)

(3) p \& q (premise)

Where ' $\&$ ' stands for conjunction and the equivalences are as follows:

p: John chooses the soup'n salad special.

q: John gets free coffee.

r: John gets free cola.

s: John chooses the minute steak.

t: John gets a free glass of wine.

Obviously, step 3 refers to the fact that John chose the soup'n salad special and coffee, but the most important point here is that, as said, apparently, the rules of mental logic do not enable to respond to the questions. Only two more steps seem possible:
(4) p (S9 3)

(5) q V r (S7 1, 4)

Where ' $S 9$ ' represents the schema 9 in Braine and O'Brien (1998b). Nevertheless, as it can be noted, steps 4 and 5 are not enough to respond to the questions.

Nonetheless, Braine and O'Brien (1998c) say that individuals have certain information, provided by pragmatics, related to the described scenario. They know that the disjunction $\mathrm{q} \mathrm{V} \mathrm{r}$ is, in this case, exclusive, since it is not usual that restaurants offer free cola and free coffee with the same election and at the same time, i.e., they know that $\neg$ (q \& r). Likewise, because of their general knowledge, they also know that restaurants do not often offer a free glass of wine with food, unless otherwise explicitly indicated. They can hence think that, in that scenario, a free glass of wine is only possible if the minute steak is elected, i.e., that $\mathrm{t}->\mathrm{s}$. In the same way, because John chose the soup'n salad special, they also know that he did not elect the minute steak, i.e., they also know that $\neg \mathrm{s}$.

Therefore, given that pragmatics seems to provide three additional premises it can be stated that the real inference corresponding to this experiment is this one:

(1) $p->(q \mathrm{Vr})$ (premise)

(2) $\mathrm{s} \rightarrow \mathrm{t}$ (premise)

(3) p \& q (premise)

(4) $\neg$ (q \& r) (pragmatic premise)

(5) $t->s$ (pragmatic premise)

(6) $\neg \mathrm{s}$ (pragmatic premise)

(7) q (S9 3)

(8) $\neg \mathrm{r}(\mathrm{S} 44,7)$

(9) $\mathrm{t}$ (assumption)

(10) s (S7 5, 9)

(11) Incompatibility $(\mathrm{S} 106,10)$ 
Where ' $\mathrm{S} 4$ ' is the schema 4 in Braine and O'Brien (1998b), which is a version of Chrysippus' modus ponendo tollens, is considered to be other Core Schema in ML, and can be formally expressed in this way:

$\neg$ (A1 and... and An), Ai; ergo $\neg(\mathrm{A} 1$ and... and $\mathrm{Ai}-1$ and $\mathrm{Ai}+1$ and... An).

As can be noted, step 8 enables to answer to the question (a). Step 9 is the supposition that John gets a free glass of red wine, which, as shown in step 11, leads to an incompatibility and hence allows one to respond to the question (b), since, if an incompatibility is found after supposing $\mathrm{t}$, it is not possible.

Thus, it is clear that ML can also account for certain inferences in which it appears that there are not enough premises to draw a conclusion by applying its formal rules. This point is important because MM often resorts to inferences linked to pragmatics in its experiments and arguments. A representative example in this regard can be the following:

"Pat is in Rio or she is in Brazil.

Pat is not in Brazil.

Therefore, Pat is in Rio" (Johnson-Laird, 2010, p. 206).

According to Johnson-Laird (2010), most individuals do not accept this inference because their knowledge blocks one of the possible scenarios. In principle, the possibilities would be:

Pat is in Rio and Pat is in Brazil

Pat is in Rio and Pat is not in Brazil

Pat is not in Rio and Pat is in Brazil

Nonetheless, given that it is known that Rio is a city in Brazil, individuals tend to reject the second model (Pat is in Rio and she is not in Brazil). Johnson-Laird (2010) thinks that this phenomenon is very hard to explain for the formal rules theories, since the inference refers to a formal structure that holds in standard propositional calculus. That structure is Chrysippus' modus tollendo ponens and, as far as the aim of this paper is concerned, the problem is that, as said, Braine and O'Brien's (1998b) schema 3 is a version of it.

However, that problem can disappear if we pay attention to the fact that Johnson-Laird (2010) acknowledges that the formal theories have an argument in their defense. There can be a hidden or implicit premise, which is not said, but is taken into account by people. In this case, the premise could be, for example, 'if Pat is in Rio then she is in Brazil'. Thus, this premise, along with the third one (Pat is in Rio), enables to draw, by modus ponens, or, if preferred, by $\mathrm{S} 7$, that Pat is in Brazil, which, along the second premise (Pat is not in Brazil), leads in turn to an inconsistency or incompatibility (Pat is not in Brazil and she is in Brazil). This account is absolutely consistent with ML, since this latter theory, as explained, admits that pragmatics plays a role in human inferential activity, and it is obvious that pragmatics can give us a premise such as 'if an individual is in Rio then that individual is in Brazil'. Most of us know that being in Rio involves being in Brazil.

\section{Contradictions do not enable to derive everything.}

But Johnson-Laird (2010) continues to question this last account. His argument is that, in standard propositional calculus, a contradiction (for example, Pat is in Brazil and Pat is not in Brazil) allows one to deduce any formula, which means that the use of the Reductio ad Absurdum Strategy should lead to scenarios in which everything is possible, and that, when a contradiction is found (as in the case of the previous example), everything can be concluded.

Nonetheless, the response to this objection seems to be simple and Braine and O'Brien (1998d) offer it. According to them, contradic- 
tions do not play the same role in human reasoning as in standard propositional calculus. Indeed, in standard propositional calculus, an inconsistency enables to deduce any formula. However, in mental logic (or, if preferred, in human reasoning), contradictions only reveal that at least one of the premises or assumptions is false and that it (or, if that is the case, they) must be rejected.

Given these three reasons, it can be thought that it is obvious that ML continues to be a valid alternative for accounting for human reasoning. However, I think that MM can respond to them without too much difficulty.

\section{The responses of $\mathrm{MM}$}

Really, in my view, MM can in turn respond to these three arguments in a very easy way. On the one hand, it is true that ML does not claim that the human mind is able to solve all of the reasoning tasks that can be proposed. As said, according to ML, individuals only resolve those tasks in which schemata accepted by it must be used. However, the advantage of $\mathrm{MM}$ in this regard is that its approach is not only the result of empirical studies. It is also a theoretical framework that can account for the reasons of most individuals' responses in most of the reasoning tasks, whether such responses are consistent with standard logic or not. In this way, while the argument of ML is simply that people do not usually make certain inferences, MM explains why they do not make them and predict the majority answers. As indicated, in the case of the example of David, Paris, and England taken from Orenes and Johnson-Laird (2012), MM claims that the reason is that one of the possibilities to which the sentence 'David visited Paris or he visited England' refers is 'David visited Paris and David did not visit England', i.e., a possibility in contradiction with the premise 'David visited England'. However, ML only argues that the empirical data show that individuals do not often use the disjunction introduction rule.
On the other hand, it is also true that ML is a modest theory that is not intended to account for all of the cognitive phenomena. In this way, the idea that ML and MM can cohabit seems to be opportune and make sense. Nevertheless, the problem is that the case is not that MM explains certain results that ML cannot. The point is that what actually happens is that MM explains all of the results that can be explained by ML and, in addition, other cognitive phenomena related to the human inferential activity that ML cannot. For example, as mentioned, MM gives the reasons why people apply the disjunction introduction rule in certain circumstances and, for the moment, if López-Astorga's (2015a) paper is ignored, ML does not. So, the fact that some experimental results can only be explained by MM is a problem for ML. The reason is that the current situation is not that both theories explain different phenomena. The scenario is nowadays that MM accounts for more phenomena and results than ML.

As far as pragmatic is concerned, the fact that ML resorts to it proves, at least, that logical form is not the only important factor in reasoning. But, if this is so, this last theory must acknowledge that the meaning of the words used in the inferences is relevant too, and maybe semantics as well. In this way, the role that the meaning of words such as 'cola', 'coffee', or 'restaurant' in the experiment reported by Braine and O'Brien (1998c) and such as 'Rio' and 'Brazil' in the example taken from JohnsonLaird (2010) plays is obvious. The arguments exposed by Johnson-Laird in this latter paper can be very illustrative in this way.

Finally, although we accept the ML thesis that contradictions only reveal that one (or more) of our assumptions or suppositions is (or are) wrong, certain grey areas remain. If a particular inference includes several assumptions, how do we know which the incorrect one (or ones) is (or are)? What is the mechanism to discover that? Considering the example coming from Johnson-Laird (2010) again, which is the false 
premise, 'Pat is in Rio or she is in Brazil', 'Pat is not in Brazil', or both of them? (as far as this point is concerned, López-Astorga's, 2016b, p. 47, arguments are also very illustrative). Obviously, ML needs to clarify points such as these ones, and this circumstance suggests that, at present, $\mathrm{MM}$ is a better alternative and that the reasons that the proponents of ML can offer are not enough.

\section{Conclusions}

There is no doubt that MM is a powerful theory that, as indicated, can explain and predict most cognitive phenomena linked to reasoning. My aim in this paper was not to deny this fact. My only goal was to analyze certain arguments that can be given from ML in order to show that, despite the empirical evidence, it continues to be reasonable to accept its general framework, and to check whether or not such arguments are solid enough to consider ML to be an alternative to MM. Unfortunately, my conclusion is that this is not, at least clearly, the case at present.

ML seems to be only based on experimental results. However, MM not only focuses on empirical data. It is a theoretical approach with important philosophical roots that trace back to Peirce (1931-1958), as acknowledged by Johnson-Laird (2012), and his idea of iconic representations. In this way, MM is able to provide an account of the deep causes of human intellectual behavior. Thus, it does not only indicate which the reasoning tasks that individuals usually solve in accordance with standard logic are, but also why the answers to the other tasks are often incoherent with that logic and which the responses expected to them are. Evidently, ML does not achieve this level of depth yet, but maybe it could do that if paid more attention to its theoretical bases. Braine and O'Brien (1998c) refer to ideas proposed by Fodor (1975) and Macnamara (1986) regarding the thesis of a language of thought and perhaps this could be the way ML could improve in this sense.
Of course, it is absolutely possible that there is a syntax leading human inferential activity. Nevertheless, the point is that the evidence suggests otherwise. MM demonstrates that human reasoning can be explained without resorting to syntax, but ML cannot prove that human reasoning can be accounted for without resorting to semantics. The pure logical forms are not enough in this latter theory, and, as indicated, it needs to consider the meaning of the words appearing in the inferences. As far as this point is concerned, probably a possible solution would have to show a syntax underlying to the process of detection or identification of models. If, although modulation can eliminate models, the connectives (conditional, conjunction, disjunction,...) use to always refer to models with similar structures (e.g., the conditional use to always have the same mental model and the same fully explicit models), that circumstance can reveal the existence of a hidden syntax. Obviously, ML also needs to work on this issue.

Furthermore, other dark spots are to be found in ML. This is the case of, for example, contradictions. It is true that ML claims that the role of incompatibilities in human reasoning is not related to Ex Contradictione Quodlibet principle (any formula can be derived from a contradiction), but to Reductio ad Absurdum. Still, in the situations in which there are several assumptions, this theory needs, as said, to explain in greater details which of those assumptions are rejected by the contradiction and how that is decided.

A possible option can be to continue to develop López-Astorga's (2013, 2014c) arguments and to try to find correspondences between semantic approaches such as MM and syntactic frameworks. As it is well known, in standard logic, the rules are coherent with truth tables. For example, the modus ponens rule has a truth table in which, when the premises are true, the conclusion is also necessarily true. In other words, if we assume that ' $v$ ' represents the truth value of the formula that follows between 
brackets and that ' 1 ' stands for truth, it can be said that, when $\mathrm{v}(\mathrm{p}->\mathrm{q})=1$ and $\mathrm{v}(\mathrm{p})=1$, necessarily $\mathrm{v}(\mathrm{q})=1$. Maybe this correspondence also exists in human reasoning and the mental models of MM are coherent with the formal rules of ML. In short, both theories admit that pragmatics has a role. In MM it can block models and in ML it can provide premises. Nevertheless, even if this idea was accepted, a problem would remain: it would be necessary to determine which the basic, actual, and primitive mental process is, i.e., whether the basic, actual, and primitive mental process is semantic or syntactic. Perhaps it is syntactic, but the empirical findings of MM do not enable to ignore the idea that semantic alone can account for human reasoning, and that syntax alone cannot, since it needs the help of semantics (at least for now, since, as far as I know, arguments in favor of a syntax underlying to the models of MM have not provided yet).

In view of all that, maybe another choice can be that indicated by ML regarding exclusivity. Thus, we can accept the theory that appears to be more coherent and consistent with reality or empirical findings, but we should not ignore the possibility that one or more of the other approaches is correct at the same time. The problem about this choice is that, so far, MM seems to be able to explain everything that can be accounted for by the rival theories and, in addition, more phenomena. Therefore, apart from the fact that the principle of parsimony can be invoked in this controversy, it is obvious that, if ML wishes to continue to be an alternative to MM, it must clarify the points indicated in this paper and develop to a greater extend their theses.

\section{References}

Braine, M. D. S., \& O’Brien, D. P. (Eds.). (1998a). Mental Logic. Mahwah, NJ: Lawrence Erlbaum Associates, Inc., Publishers.

Braine, M. D. S., \& O’Brien, D. P. (1998b). The theory of mental-propositional logic:
Description and illustration. In M. D. S. Braine \& D. P. O’Brien (Eds.), Mental Logic (pp. 79-89). Mahwah, NJ: Lawrence Erlbaum Associates, Inc., Publishers.

Braine, M. D. S., \& O'Brien, D. P. (1998c). How to investigate mental logic and the syntax of thought. In M. D. S. Braine \& D. P. O'Brien (Eds.), Mental Logic (pp. 45-61). Mahwah, NJ: Lawrence Erlbaum Associates, Inc., Publishers.

Braine, M. D. S., \& O’Brien, D. P. (1998d). A theory of if: A lexical entry, reasoning program, and pragmatic principles. In M. D. S. Braine \& D. P. O'Brien (Eds.), Mental Logic (pp. 199-244). Mahwah, NJ: Lawrence Erlbaum Associates, Inc., Publishers.

Byrne, R. M. J., \& Johnson-Laird, P. N. (2009). "If" and the problems of conditional reasoning. Trends in Cognitive Science, 13, 282-287.

Evans, J. St. B. T. (2008). Dual-processing accounts of reasoning, judgment, and social cognition. Annual Review of Psychology, 59, 255-278.

Fodor, J. (1975). The Language of Thought. Cambridge, MA: Harvard University Press.

Gentzen, G. (1935). Untersuchungen über das logische Schließen. I. Mathematische Zeitschrift, 39, 176-210.

Johnson-Laird, P. N. (1983). Mental Models. Towards a Cognitive Science on Language, Inference, and Consciousness. Cambridge, MA: Harvard University Press.

Johnson-Laird, P. N. (2001). Mental models and deduction. Trends in Cognitive Science, $5,434-442$.

Johnson-Laird, P. N. (2006). How We Reason. Oxford, UK: Oxford University Press. 
Johnson-Laird, P. N. (2010). Against logical form. Psychologica Belgica, 5(3-4), 193221.

Johnson-Laird, P. N. (2012). Inference with mental models. In K. J. Holyoak \& R. G. Morrison (Eds.), The Oxford Handbook of Thinking and Reasoning (pp. 134-145). New York, NY: Oxford University Press.

Johnson-Laird, P. N. (2015). How to improve thinking. In R. Wegerif, L. Li, \& J. C. Kaufman (Eds.), The Routledge International Handbook of Research on Teaching Thinking (pp. 80-91). Abingdon, UK, \& New York, NY: Routledge.

Johnson-Laird, P. N., Byrne, R. M. J., \& Girotto, V. (2009). The mental models theory of conditionals: A reply to Guy Politzer. Topoi, 28, 78-80.

Khemlani, S., \& Johnson-Laird, P. N. (2009). Disjunctive illusory inferences and how to eliminate them. Memory \& Cognition, 37(5), 615-623.

López-Astorga, M. (2013). Are conditional and disjunction really comparable? Universum, 28(2), 229-242.

López-Astorga, M. (2014a). A formal theory can explain disjunctive illusory inferences. Círculo de Lingüística Aplicada a la Comunicación, 60, 122-143.

López-Astorga, M. (2014b). The mental logic theory and DeMorgan's laws. International Journal of Humanities and Social Science, 4(11-1), 24-28.

López-Astorga, M. (2014c). Mental models and syntactic rules: A study of the relations between semantics and syntax in inferential processes. Annals of the University of Craiova, Philosophy Series, 31(1), 107-117.
López-Astorga, M. (2015a). The disjunction introduction rule: Syntactic and semantic considerations. Pragmalingüística, 23, 141-149.

López-Astorga, M. (2015b). The case of the conditionals with disjunctions embedded into their antecedents: Mental logic versus semantic models. Universum, $30(2), 143-152$.

López-Astorga, M. (2015c). The formal discipline theory and mental logic. Praxis Filosófica, 41, 11-25.

López-Astorga, M. (2016a). Mental logic and the denials of conjunctions and disjunctions. Trans/Form/Ação, 39(1), 119-138.

López-Astorga, M. (2016b). The principle of explosion: Aristotle versus the current syntactic theories. Schole, 10(1), 40-49.

Macnamara, J. (1986). A Border Dispute: The Place of Logic in Psychology. Cambridge, MA: Massachusetts Institute of Technology (MIT) Press.

Oakhill, J., \& Garnham, A. (Eds.). (1996). Mental Models in Cognitive Science. Essays in Honour of Phil Johnson-Laird. Hove, UK: Psychology Press.

O'Brien, D. P. (1998). Mental logic and irrationality: We can put a man on the moon so why can't we solve those logical reasoning problems?. In M. D. S. Braine \& D. P. O'Brien (Eds.), Mental Logic (pp. 23-43). Mahwah, NJ: Lawrence Erlbaum Associates, Inc., Publishers.

O'Brien, D. P. (2009). Human reasoning includes a mental logic. Behavioral and Brain Sciences, 32, 96-97.

O’Brien, D. P. (2014). Conditionals and disjunctions in mental-logic theory: A 
response to Liu and Chou (2012) and to López-Astorga (2013). Universum, 29(2), 221-235.

O’Brien, D. P., Braine, M. D. S., \& Yang, Y. (1994). Propositional reasoning by mental models? Simple to refute in principle and in practice. Pyschological Review, 101(4), 711-724.

O’Brien, D. P. \& Li, S. (2013). Mental logic theory: A paradigmatic case of empirical research on the language of thought and inferential role semantics. Journal of Foreign Languages, 36(6), 27-41.

Orenes, I., \& Johnson-Laird, P. N. (2012). Logic, models, and paradoxical inferences. Mind \& Language, 27(4), 357-377.

Peirce, C. S. (1931-1958). Collected Papers of Charles Sanders Peirce (Vols. 1-8, C. Hartshorne, P. Weiss, \& A. Burks Eds.). Cambridge, MA: Harvard University Press.

Reyna, V. F. (2004). How people make decisions that involve risk: A dualprocess approach. Current Directions in Psychology Science, 13, 60-66.
Rips, L. J. (1994). The Psychology of Proof: Deductive Reasoning in Human Thinking. Cambridge, MA: Massachusetts Institute of Technology (MIT) Press.

Schroyens, W. J., Schaeken, W., \& D'Ydewalle, G. (2001). The processing of negations in conditional reasoning: A meta-analytic case study in mental model and/or mental logic theory. Thinking \& Reasoning, 7(2), 121-172.

Stanovich, K. E. (1999). Who is Rational? Studies of Individual Differences in Reasoning. Mahwah, NJ: Erlbaum.

Stanovich, K. E. (2004). The Robot's Rebellion: Finding Meaning in the Age of Darwin. Chicago, IL: Chicago University Press.

Stanovich, K. E. (2012). On the distinction between rationality and intelligence for understanding individual differences in reasoning. In K. Holyoak \& R. Morrison (Eds.), The Oxford Handbook of Thinking and Reasoning (pp. 343-365). New York, NY: Oxford University Press. 
